\title{
Can prophylactic cholecystectomy be justified?
}

\author{
Jung Ho Shim $\cdot$ Cho Hyun Park $\cdot$ Kyo Young Song
}

Received: 12 September 2012/ Accepted: 1 November 2012/Published online: 22 December 2012

(c) The International Gastric Cancer Association and The Japanese Gastric Cancer Association 2012

Keywords Prophylactic cholecystectomy · Gastric cancer · Gastrectomy

To the Editors:

The incidence of gallstones and associated cholecystitis is known to be higher in patients after gastrectomy than in the general population. The hypothesis for this high incidence of cholelithiasis is the surgical dissection of the vagal nerve branches. Acute cholecystitis can lead immunocompromised cancer patients to severe complications, including sepsis, and even to death. Therefore, some surgeons advocated concomitant cholecystectomy during the gastric cancer operation because it might carry the minimal range of risk [1]. The Japanese surgeons proposed vagus nerve preservation during radical gastrectomy to preserve normal intestinal and biliary function after gastrectomy [2].

The Italian surgeons had questions about prophylactic cholecystectomy at the time of gastrectomy and started a prospective randomized trial to investigate the incidence of cholelithiasis after gastric cancer surgery and the outcomes of concomitant cholecystectomy [3]. Recently, we read the article "The Cholegas Study: safety of prophylactic cholecystectomy during gastrectomy for cancer: preliminary results of a multicentric randomized clinical trial" by Bernini et al. [4] in the E-pub issue of Gastric Cancer with interest. In their study, cholecystectomy did not increase the postoperative morbidity, mortality, or costs.

This letter refers to the article doi:10.1007/s10120-012-0195-9.

J. H. Shim · C. H. Park · K. Y. Song $(\bowtie)$

Department of Surgery, Seoul St. Mary's Hospital,

College of Medicine, The Catholic University of Korea,

505 Banpo-dong, Seocho-gu, Seoul 137-701, Korea

e-mail: skys9615@gmail.com
This is a very interesting study. However, we are concerned about several issues, including the ethical problems.

Although we admit that vagal denervation could increase the risk of gallstone formation and subsequent acute cholecystitis with stones, and this can cause serious complications including sepsis in a gastrectomized patient, the actual number of patients who might need surgery for it is quite small. Also, the presumed serious postoperative complication after cholecystectomy in patients with gastrectomy is also rare. The operative risk of metachronous cholecystectomy is not well defined. Rather, a minimally invasive approach can safely be applied to patients with cholecystitis and even to those with choledocholithiasis [5].

Although gastrectomy could increase the risk of gallstones and concomitant cholecystectomy does not increase postoperative morbidity, this reasoning does not fully support the ethics and rationale of proposing prophylactic cholecystectomy for a patient with a normal gallbladder. Most of the patients, at least $75 \%$, will not have gallstone disease, and possibly can experience functional digestive problems as a result of unnecessary cholecystectomy. We believe that the operative risk for patients with cholecystitis after gastrectomy and the digestive problems after cholecystectomy should also be discussed if the authors claim the necessity of prophylactic cholecystectomy during gastrectomy.

Conflict of interest All authors have no conflict of interest.

\section{References}

1. Akatsu T, Yoshida M, Kubota T, Shimazu M, Ueda M, Otani Y, Wakabayashi G, Aiura K, Tanabe M, Furukawa T, Saikawa Y, Kawachi S, Akatsu Y, Kumai K, Kitajima M. Gallstone disease after extended (D2) lymph node dissection for gastric cancer. World J Surg. 2005;29:182-6. 
2. Ando S, Tsuji H. Surgical technique of vagus nerve-preserving gastrectomy with D2 lymphadenectomy for gastric cancer. A N Z J Surg. 2008;78:172-6.

3. Farsi M, Bernini M, Bencini L, Miranda E, Manetti R, de Manzoni G, Verlato G, Marrelli D, Pedrazzani C, Roviello F, Marchet A, Cristadoro L, Gerard L, GIRCG (Gruppo Italiano di Ricerca sul Cancro Gastrico). The CHOLEGAS study: multicentric randomized, blinded, controlled trial of gastrectomy plus prophylactic cholecystectomy versus gastrectomy only, in adults submitted to gastric cancer surgery with curative intent. Trials. $2009 ; 15(10): 32$.
4. Bernini M, Bencini L, Sacchetti R, Marchet A, Cristadoro L, Pacelli F, Berardi S, Doglietto GB, Rosa F, Verlato G, Cozzaglio L, Bechi P, Marrelli D, Roviello F, Farsi M, Italian Research Group for Gastric Cancer (IRGGC). The Cholegas Study: safety of prophylactic cholecystectomy during gastrectomy for cancer: preliminary results of a multicentric randomized clinical trial. Gastric Cancer 2012 [Epub ahead of print].

5. Kim J, Cho JN, Joo SH, Kim BS, Lee SM. Multivariable analysis of cholecystectomy after gastrectomy: laparoscopy is a feasible initial approach even in the presence of common bile duct stones or acute cholecystitis. World J Surg. 2012;36:638-44. 